\title{
American PARCC and SBAC and Their Implications on the Construction of English Assessment System in China
}

\author{
Haiyan Zhang ${ }^{1} \&$ Kai Kang ${ }^{1}$ \\ ${ }^{1}$ School of Foreign Studies, Nantong University, Jiangsu, China \\ Correspondence: Haiyan Zhang, School of Foreign Studies, Nantong University, Jiangsu, China. E-mail: \\ hldhaiyan@163.com
}

Received: August 12, 2016

doi:10.5539/ies.v10n1p190

\author{
Accepted: September 22, $2016 \quad$ Online Published: December 26, 2016 \\ URL: http://dx.doi.org/10.5539/ies.v10n1p190
}

\begin{abstract}
The Partnership for Assessment of Readiness for College and Careers (PARCC) and Smarter Balanced Assessment Systems (SBAC) started in the 2014-2015 academic year and has been regarded by many in the field as a radical effort to improve the American English Language Art (ELA) educational standards. These two consortia, being aligned with Common Core State Standards, aim to fulfill Common Core's purpose of preparing students for college and career readiness. With the support of computer technology, diverse forms of testing are introduced into the new assessment systems, making the standard-based test comprehensive enough to evaluate academic literacy and deep learning capacity in an authentic way.

This paper mainly discusses similarities and differences between the two assessment systems in terms of ELA standards. The similarities appear in the construction of well-balanced assessment structure, the application of advanced computer technology, adherence to an evidence-based design principle and emphasis upon educational equity. The key differences are presented in aspects of test forms and accommodation options. The analysis of PARCC and SBAC assessment systems also provides China with various thought provoking aspects to develop a sound English Language assessment system.
\end{abstract}

Keywords: English language assessment system, Partnership for Assessment of Readiness for College and Careers (PARCC), Smarter Balanced Assessment System (SBAC)

\section{Introduction}

The Outline of the National Medium and Long Term Educational Reform and Development Plan proposes that improving the educational quality ought to be the core task among educational reform. In order to promote English education in China, it is imperative to establish a sound English language assessment system in accordance with a curriculum standard. However, the English language assessment standard was ignored in curriculum reform. Although the National English Curriculum Standard was launched in 2011 in China, it only contains assessment advice and lacks detailed assessment standards, leaving insufficient scientific references for teachers setting assessments methods in reading, speaking, listening and writing sections in English tests, restraining the implementation of the new curriculum. English educators in China often resort to outdated assessment methods and a single type of testing question, evaluating students' abilities of rote learning and neglecting their advanced cognitive skills such as critical thinking, inquiry, and problem-solving ability. In this regard, English teaching quality is no doubt affected in a negative way. The deficiency of English academic assessment has aroused attention. In 2014, a conference on foreign language proficiency assessment took place in Beijing. In the conference, the goal and scheme for constructing well-balanced national assessment system for foreign languages abilities were clarified, which promoted the development of English language testing system in China.

Meanwhile, the U.S. has constructed two assessment systems in accordance with Common Core State Standards (CCSS)-the Partnership for Assessment of Readiness for College and Careers (PARCC) and Smarter Balanced Assessment Consortium (SBAC), setting a worthy example for China to explore. These two assessments systems share the same goal of developing some specific tests to prepare students toward success in college and a future career. PARCC and SBAC started in the 2014-2015 academic year and have been regarded as a radical effort to improve the American English Language Art (ELA) education. 
Current studies focus on the background and characteristics of these two assessments in China. So far, researches has yet to examine the similarities and differences of PARCC and SBAC and this paper will analyze, compare and contrast both assessment systems while exploring the implications for establishing Chinese assessment standards in English education.

\section{Background of Constructing PARCC and SBAC Assessment Consortia}

\subsection{Launching of the Common Core State Standards}

Since the 1990s, the United States has put great effort into standard-based reforms in order to promote the quality of fundamental education and increase its international standing. However, as each state had the right to develop its own curriculum standards, it was rather difficult for the U.S. to diminish the educational quality gap with other states. In 1991, American President George. H. Bush released America 2000-an educational strategy. This document, to some extent, embodied the intention of establishing a united national curriculum standard and standardized testing. Afterwards, in 2001, No Child Left Behind Act (NCLB) was passed, with the aim to significantly increase the federation's role in interfering in schools' measures of improving students' academic progress (McDonnell, 2005). The Act requires all schools to meet their states' curriculum standards; otherwise they would be subjected to serious sanctions. For example, if a school misses "Adequately Yearly Progress", which is an accountability tool to keep schools on track toward their goals, for three years in a row, the school must offer free tutoring. However, many school were not able to meet the NCLB's demands, thus a large number of states lowered their achievement standards so as to escape from severe sanctions. The achievement gaps among states were further widened. In order to promote the quality of national education as well as adequately prepare students with skills and knowledge for global competition, in June 2010, the Common Core State Standard for grades K-12 in English language arts and mathematics was launched. The National Governors Association and the Council of Chief State School Officers sponsored this state-led initiative.

\subsection{Calling for Assessment Standards Reform}

In September 2010, the U.S. Secretary of Education Arne Duncan addressed a speech called Beyond the Bubble Tests: The Next Generation of Assessments. In the speech, he said that the complaints he heard from teachers were mostly about demerits of bubble tests, which could not test students' skills that really matter in society (U.S. Department of Education, 2010). The deficiency of the old U.S assessment system was shown in two ways. On one hand, states assessment standards were mainly designed to standardized tests in NCLB, which were unscientific and ineffective. They mainly focused on whether students could pass English exams rather than testing students' critical thinking, problem-solving and deep-learning abilities. On the other hand, the assessment results of each state were incomparable, as each individual state had developed its own standards that were not adaptive to CCSS (Doorey, 2012). Under such circumstances, establishing a set of national assessment standards for CCSS thus became a necessity. Three months after the CCSS was released, two multi-state consortia----PARCC and SBAC, were then granted by the U.S Department of Education in the Race to the Top competition with $\$ 170$ million and $\$ 160$ million respectively to set up the new generation of assessment system. Now, 15 states have joined SBAC led by Washington State. The PARCC led by Florida, is made up of 11 partners including the 8 fully-participating states (Howard, 2015).

\section{Similarities between PARCC and SBAC}

\subsection{Well-Balanced Assessment Structure}

In an effort to provide teachers and students with ongoing and valid assessment, PARCC and SBAC developed combined summative and formative assessments that can comprehensively evaluate students' English language competency in an authentic way.

The assessment structure developed by PARCC consists of summative assessment, formative assessment and speaking \& listening assessment. The summative assessment including the performance-based assessment and the end-of-year assessment, aims to test Grade 3-8 and high school students' progress toward readiness for college and career. The performance-based assessment will be taken close to the end of school year and scored by a mix of humans and computers. This kind of assessment mainly concentrates on hard-to-measure standards. Narrative Task (NT), Literary Analysis Task (LAT) and Research Simulation Task (RST) constitute performance tasks. Tasks include short texts and extended texts for different grades students, using Evidence-Based Selected Response (EBSR) questions and Technology-Enhanced Constructed Response (TECR) questions. End-of-year assessment will be taken after $90 \%$ of the instructional time for the semester has occurred. It mainly focuses on assessing students' reading comprehension. A wide range of innovative questions will be adopted in this assessment which includes EBSR and TECR. Formative assessment in PARCC is composed of diagnostic 
assessment and mid-year assessment. PARCC's schedule begins with a diagnostic test at the start of the year, designed to provide teachers with a sense of their students' knowledge and inform their instruction. PARCC has also developed formative tools to provide teachers with effective instructional information. On the strength of such tools, teachers can get timely feedback, with which they would accordingly adjust the teaching plans or methods. Diagnostic assessments with elemental results can pinpoint students' strengths and needs. They help teachers tailor appropriate instructional plans so as to track students' progress to satisfy student needs. Featuring multiple performance tasks, mid-year assessments update educators on their students' progress. It is up to states whether to add the results of mid-year assessments to the summative assessment or not. All participants of states in PARCC are required to take speaking and listening assessments as well, although the results will not be included in the summative score. Students may be asked to do an oral presentation or demonstrate their ability to understand complex information through performance-based tasks or classroom discussion rubrics at any time during each academic school year.

The Smarter Balanced assessment system consists of three parts-summative assessment for accountability purposes, classroom-based formative assessments and interim assessments to improve student's study and teaching throughout the academic year. Likewise, the summative assessment in SBAC is made up of computer adaptive tests and performance tasks. These tests are conducted at the end of academic year. For those states without supporting computer devices, the SBAC will offer them paper-based tests for three years as transition phase. One unique feature of SBAC summative assessment is that students can retake the test with renewed items if it is locally allowed. The Smarter Balanced consortium also created the Digital Library where high quality instructional teaching resources are provided for educators online. With the help of these rich resources, teachers can monitor students' learning progress and design instructional targets for different learners. Optional interim assessments allow teachers to track student progress throughout the year, giving them information that can improve teaching instruction and help students meet the challenge of college- and career-ready standards. Interim Comprehensive Assessment (ICAs) and Interim Assessment Blocks (IABs), two online tests, are included in optional interim assessment. ICAs test the same content and report scores on the same scale as the summative assessments, while IABs focus on smaller sets of concepts and provide more detailed information for instructional purposes. Most of interim assessments will be scored via computers. Educators are likely to score some constructed response items with invalid computer scoring.

\subsection{Computer Technology Based Assessment}

Instead of barely relying on traditional paper-tests, both PARCC and SBAC adopt computer technologies to assess Grade3-8 and high school students' achievements in ELA. Using computer as an assessment tool has clear advantages in receiving timely feedback from students, teachers as well as parents. Multiple assessment items and assessment equity for students with special needs are guaranteed.

Computer-based assessment tests are very interactive, making it able to provide great convenience for students and teachers. In PARCC online ELA tests, students can click icons such as "Review" to switch questions quickly, "Bookmark" to mark questions for review, "Notepad" to take notes and "Answer eliminator" to cross out answer choice. Moreover, while students doing the test, they can choose the answers by clicking sentences in the text or simply drag options to the answer square, which save students great time in copying sentences from reading passage by writing. More importantly, compared to paper-and-pencil tests, technology- enhanced constructed response can promote testers' creative skills. By sorting, pasting or organizing elements offered in the test, students have variety of ways to present their progress in cognitive skills. PARCC has also been developing the Partnership Resource Centre, an Internet platform where participants can cooperate to create teaching plans and curriculum structure. What is more, it also contains a multitude of high-quality tests for teachers. Similarly, SBAC digitally-delivered assessments provide students with many tools such as "Highlighter", "Spell Check", and "English Dictionary" (Smarter Balanced Assessment Consortium, 2015). Taking advantage of the computer adaptive technology, the test results could be far more precise and descriptive. The difficulty level of tests will be set according to students' responses after they take the test. In other words, if a student does well, he will take the harder section, and vice versa. This technology can better identify students' weaknesses and locate their performance level. Since the SBAC system is managed online, the assessment results of students can be reported to teachers and parents much quicker than those of traditional tests. In this way, teachers can adjust their teaching plans and teaching methods according to assessment results. PARCC is also planning to use computer adaptive technologies to study students' zone of proximal development. 


\subsection{Universal Design for Educational Equity}

With the help of computer technologies, PARCC and SBAC also strive to create an equal environment of high-quality assessments for students. The concept of "universal design", as a core principle being adopted in designing assessment items and performance tasks, acknowledges students' differences and builds flexible assessments for a broad range of students. Actually, the core of universal design is that every child has right to be tested in schools. Embedding the feature of accessibility, PARCC can give the greatest number of students, whether gifted or disabilities, the opportunity to demonstrate what they have learned. In addition, PARCC takes accommodation into consideration to adjust test format and test conditions, so that disabled students could have equal access to assessments. For instance, during computer-based tests, students who are blind or have visual impairment can take advantage of their preferred "Screen Reader version" software or "Large Print Edition" to complete the test. Apart from that, they can also have the graphics portion of test questions and visual descriptions of pictures and multimedia. For those students with print-related disabilities, they can take tests by embedded "Text-to-speech" and "Human reader/human signer" accommodation through which students can receive an audio version of the text. While listening to the audio, students can control the speed of reading and change volume as well. Likewise, the accessibility for all students is the core principle held by SBAC. With the help of technology, SBAC has been developing a variety of universally accessible tools, designated supports and accommodations aiming to eliminate visual, auditory and physical access barriers. For example, students with difficulty in concentration can chose "Color contrast" or "Masking" supports. Online texts may be printed in different colors or students can hide some contents for later use.

\subsection{Evidence-centered Design}

PARCC and SBAC regard the Evidence-centered Design (ECD) as their principled approach to construct valid assessments based on evidentiary argument. Educational assessment should address three main questions: what knowledge and skills should be assessed? What evidence can demonstrate that students have mastered these knowledge and skills? What kind of assessment tasks or items can elicit such skills? ECD starts with the basic premise that assessment is a process of reasoning from evidence to evaluate specific claims about students' capability. In essence, students' responses to assessment items and tasks provide the evidence to the reasoning process, and psychometric and other validity analyses establish the sufficiency of the evidence for evaluating each claim (PARCC, 2016). For instance, in ELA tests from PARCC, students shall read one or several texts, answer questions or write short essays based on the reading passage and provide evidence in the text to support their answers. Sometimes, students are also required to defend their ideas by composing an essay, which means that they have to present a thorough and coherent explanation rather than a simple answer. Since this skill is imperative in college and workplace, it is vital for students to master it. Examples of PARCC test items can be seen in "Me First" text as below:

Part A

How do Pinkerton's actions lead him to be tricked by the Sandwich?

A. Pinkerton thinks only about himself, so he keeps the Scouts from meeting the Sandwich.

B. Pinkerton cares more about eating than helping his fellow Scouts, so he keeps the Sandwich a secret.

C. Pinkerton wants to be better than the other Scouts, so he volunteers to help the Sandwich.

D. Pinkerton wants to arrive before everyone, so he runs ahead of the Scouts towards the sound of the Sandwich's voice

Part B:

Which detail from "Me First" supports the answer to Part A?

A. "Pinkerton was first on the bus and sat in the front row."(Paragraph 5)

B. "As the Pig Scouts marched across the sand; they heard a faint voice far in the distance.”(Paragraph 7)

C. "ME FIRST!" cried Pinkerton, kicking up sand and leaving the other Pig Scouts far behind."(Paragraph 10)

D. "A slab of cheese! A blob of mayo! A smear of mustard. All for ME! FIRST!'(Paragraph 10)

PARCC and SBAC took four steps to design assessment items aligned to ECD principle. Firstly, it identifies different claims for students of different levels about their competency in ELA from CCSS. Secondly, according to the curriculum standards SBAC sets specific assessment targets for students at each stage. Then, evidence is collected to back up those assessment targets. At last, item writers design items and tasks in accordance with the 
domains circumscribed by the claims, assessment targets and evidence.

\section{Differences between PARCC and SBAC}

\subsection{Adaptive Assessment vs. Fixed-Form Assessment}

PARCC sets summative assessments with fixed-form tests for students from grades 3 to11, while SBAC only sets for students of Grades 3-8 and Grade11 students with the support of computer adaptive assessments. As has simply illustrated before, computer adaptive test provides better, faster, and more accurate data. Such assessment concentrates on Depth of Knowledge levels that permit various results for students. Adaptive tests begin with a large item base, for 30 question tests, that base may contain 600 different questions. Each question is chosen by computer automatically based on students' previous responses. The more questions students answer correctly, the more challenging the questions would become. But if students get stumbled, the question would become easier, depending on his or her skill level. On the contrary, PARCC assessment system takes a fixed-form delivery model, which means that regardless of a student's status at the earlier stage, educators want students to finish the year performing at grade level. The fixed testing models would determine whether that goal is achieved.

\subsection{Accommodation Options}

Even though both consortia take advantage of computer technologies to assure all students, including students with special needs, to have equitable access to tests, they differ from each other when it comes to whether "text to speech" accommodation option should be allowed in English Language Arts tests.

PARCC allows students at any grade to use the "text to speech" option during English language assessments. However, for those students who receive this accommodation, no claims should be inferred regarding their ability of demonstrating foundational reading skills (PARCC, 2016). On the other hand, the Smarter Balanced system only allows students of Grade 6 or higher to have access to "text-to-speech" accommodation, with the idea of regarding reading as the tool to test students' decoding ability.

The two assessment systems also differ in terms of glossaries provided. The SBAC has computer-based glossaries in Arabic, Cantonese, Filipino, Korean, Mandarin, Punjabi, Russian, Spanish, Ukrainian, and Vietnamese, while the glossaries of PARCC are only available in paper-based tests （Howard, 2015).

\section{Implications for Establishing Chinese National English Assessment System}

Although the National English Curriculum Standard was launched in 2011 in China, it only contains suggestions on assessment rather than assessment standards accommodated with the curriculum standards. Some English educators in China often use outdated assessment methods and neglect the test of students' advanced cognitive skills such as critical thinking, inquiring ability and problem-solving ability. The design and implementation of American PARCC and SBAC will provide a good reference for China to establish its own assessment system.

\subsection{Setting up a Comprehensive Assessment System}

One of the common characteristics of PARCC and SBAC consortia is that both of them combine summative and formative assessments together to monitor students' academic progress and prepare them for college and career. Summative assessments are often of high-stake but can't measure students' learning progress. In order to complement this deficiency, formative assessments, which have multiple forms such as classroom-based activities, informal tests and asking questions should be used. Based on the immediate feedbacks from formative assessments, teachers can reflect on their teaching process and make timely adjustments, while students can develop their self-assessment. If summative assessment is taken at the end of the academic year, then formative assessment may be taken throughout the whole academic year. Nevertheless, English teachers in China now rely heavily on standardized tests like summative assessments, and ignore the significance of formative assessments. Since standardized test items are not parallel with typical classroom skills and behaviors, teachers cannot attain the dynamic information data of students' learning process, which attributes to ineffective teaching and learning. PARCC and SBAC also have developed lots of assessment items, such as constructed-response items, extended-response items, technology-enabled items and technology-enhanced items, so as to access students' higher level of thinking skills. However, in China, English assessment items mainly consist of closed questions to test students' English basic knowledge. Their logical thinking and problem solving abilities, which will make them more competitive in the global world, are seldom tested. Thus, it is quite urgent for Chinese English educators to learn from the PARCC and SBAC consortia, combing summative and formative assessments together, and designing multi-dimensional assessment items so that students' higher-level thinking skills can be cultivated. 


\subsection{Attaching Importance to the Fairness in Education}

Almost every school in the U.S. is equipped with the Individual Education Program, aiming at working out specific educational plans for students with special needs. Thus, PARCC and SBAC assessment systems pay great attention to disabled students, and strive to offer all students equal opportunities to access to high-quality education. As for the $1 \%$ students with the most significant cognitive disabilities, states will create an alternative assessment system for them. By using universal design, taking advantage of computer technologies and embedding accommodation and accessible features in their systems, PARCC and SBAC offer disabled students chances to demonstrate their learning skills and get prepared for college and future career as ordinary students. This is an outstanding and remarkable step two assessment consortia take toward educational equity. In China, issues of educational equity mainly refer to rural migrant workers' children, disabled students, minority students and the gap between urban and rural educational resources. Despite the fact that Chinese government and all walks of life have taken many actions to assure all students have equal access to education, fairness in education hasn't been resolved since these actions lack severe supervision. Cases that disabled students are rejected by schools frequently occurs let alone favorable conditions to education. Because of these rooted problems, disabled students can't receive the same education as ordinary students, and the employment rate of disabled students is rather low. Consequently, they tend to have a much lower life quality compared with others. Therefore, it is necessary for education departments to provide the disabled students, the students in rural areas and any other minority students with equal access to education, and further develop more reasonable assessments to meet their special needs.

\subsection{Making Use of Computer Technology to Develop Online Assessment System}

Two assessment consortia both adopted computer technologies not only to design innovative technology-enhanced items, but also provide online resources and platforms for educators, students, and parents, in the hope of promoting the effectiveness of teaching and learning. Score report and guide resources are available online for educators and parents. In this way, both teachers and parents have a better understanding of their children's score results and accordingly take appropriate measures for the next step. Moreover, the link between great assessment and great instruction is demonstrated through the teaching channel videos posted by PARCC. These videos help educators design instructional tasks that can better prepare students for assessments. Likewise, SBAC has the Digital Library where professional resources and instructional models are offered. On these online platforms, educators from different states can exchange their ideas or cooperate to develop instructional tasks to meet students' needs. Computer technologies used by these two consortia make education more efficient, and eliminate the education gap among different states. Nowadays, computer technology is playing an important role in education in China. More and more classrooms are equipped with multi-media devices. With the help of advanced computer technology, English teachers can present knowledge points vividly, and students can have deeper impression about what the teachers teach. Even though computer technology has been incorporated into the teaching process, smart technology hasn't been used widely in assessments. In addition, it is necessary to invent an online platform where English teachers can exchange their assessment information and learn from each other, as well as assess students' English learning efficiently.

\section{Conclusion}

Constructing a sound assessment system is a significant way to improve quality of basic education, enhance the reliability and validity of student assessment and promote the high-stake standardized tests reform. At present, China still lacks a united assessment system and new curriculum standards for English, which restrains the implementation of curriculum standards as well as the reform of high-stake examinations. Chinese English teachers in China tend to focus on testing whether students have learned rather than finding out the important knowledge and skills that can boost learning. With high-quality assessments, teachers can not only test students' performance levels but, more importantly, foster students' high-order thinking skills which are valued in the society today. Furthermore, making use of smart technology is necessary to assure all the students can have equal chance to be educated and assessed. It is vital to form a shared online resource platform where teachers from different areas can access to great assessment modules.

\section{References}

Doorey, N. A. (2012). A New Generation of Assessments. Common Core: Now What, 4, 28-34.

Howard, A. (2015). What is the Big Difference Between PARCC and Smarter Balanced? Retrieved from http://blog.wowzers.com/what-is-the-big-difference-between-parcc-and-smarter-balanced

McDonnell, L, M. (2005). No Child Left Behind and Federal Role in Education: Evolution or revolution? 
Peabody Journal of Education, 80(2), 19-38. https://doi.org/10.1207/S15327930pje8002_2

PARCC. (2016). PARCC Accessibility Features and Accommodations Manual (5th ed.). Retrieved from http://www.parcconline.org/assessments/accessibility/manual

Smarter Balanced Assessment Consortium. (2015). End of Grant Report. Retrieved from http://www.smarterbalanced.org/wp-content/uploads/2015/08/SB-EndOfGrantReport-F2.pdf

U.S. Department of Education. (2010). Beyond the Bubble Tests: The Next Generation of Assessments-Secretary Arne Duncan's Remarks State Leaders at Achieves American Diploma Project Leadership Team Meeting. Retrieved from http://www.ed.gov/news/speeches/beyond-bubble-tests-nextgeneration-assessments-secretary-arne-duncans-remarks-state-1

\section{Copyrights}

Copyright for this article is retained by the author(s), with first publication rights granted to the journal.

This is an open-access article distributed under the terms and conditions of the Creative Commons Attribution license (http://creativecommons.org/licenses/by/4.0/). 